\title{
A TÉTRADE MCLUHANIANA COMO MÉTODO PARA INVESTIGAR AS RECONFIGURAÇÕES DO JORNALISMO NO ECOSSISTEMA MIDIÁTICO
}

\author{
THE MCLUHAN'S TETRAD AS METHOD FOR THE INVESTIGATION OF \\ JOURNALISM RECONFIGURATIONS IN THE MEDIA ECOSYSTEM \\ LA TÉTRADE MCLUHANIANA COMO MÉTODO PARA INVESTIGAR LAS \\ RECONFIGURACIONES DEL PERIODISMO EN EL ECOSISTEMA MEDIÁTICO \\ Eugenia Maria Mariano da Rocha Barichello' \\ Carolina Teixeira Weber Dall Agnese
}

Resumo: neste texto de reflexão teórico-metodológica, discute-se a adoção da tétrade de McLuhan e McLuhan (1988) como método para compor percursos de pesquisa que visem à verificação de reconfigurações nas práticas, processos e produtos jornalísticos, seja em âmbito organizacional ou institucional, no ecossistema midiático contemporâneo. Primeiramente, apresenta-se a Ecologia da Mídia como base explicativa para compreender o contexto midiático atual. Depois, apresentam-se noções e conceitos que ancoram a reflexão sobre o jornalismo, entendido como instituição social que se (re)legitima ao longo dos tempos. A seguir, aborda-se a tétrade, para, por fim, apresentar um esboço de aplicação do método adaptado.

Palavras-chave: Jornalismo. Tétrade de McLuhan. Ecossistema midiático.

Abstract: In this text of theoretical-methodological reflection, we discuss the adoption of McLuhan and McLuhan's Tetrad (1988), as a method to compose research paths that aim to verify reconfigurations in journalistic practices, processes and products in the

Doutora em Comunicação pela Universidade Federal do Rio de Janeiro (UFRJ). Professora do Programa de Pós-Graduação em Comunicação da Universidade Federal de Santa Maria (UFSM), Santa Maria, RS, Brasil. https://orcid.org/oooo-0001-5244-2829. E-mail: eugeniamarianodarocha@gmail.com

2 Doutoranda no Programa de Pós-Graduação em Comunicação da Universidade Federal de Santa Maria (UFSM), Santa Maria, RS, Brasil. https://orcid.org/o0oo-0003-1401-7500. E-mail: caroltweber@gmail.com 
contemporary media ecosystem. Firstly, Media Ecology is presented as an explanatory basis for understanding the current media context. Then, we present concepts and concepts that anchor the reflection on journalism, understood as a social institution that (re) legitimizes over time. Next, tetrad is addressed, to finally present an outline of the application of the adapted method.

Keywords: Journalism. McLuhan's Tetrad. Media Ecosystem.

Resumen: en este texto de reflexión teórico-metodológica, se discute la adopción de la Tétrade de McLuhan y McLuhan (1988), como método para componer recorridos de investigación que visen la verificación de reconfiguraciones en las prácticas, procesos y productos periodísticos en el ecosistema mediático contemporáneo. Primero, se presenta la Ecología de los Medios como base explicativa para comprender el contexto mediático actual. Después, se presentan nociones y conceptos que anclan la reflexión sobre el periodismo, entendido como institución social que se (re) legitima a lo largo de los tiempos. A continuación, se aborda la tétrica, para, por fin, presentar un esbozo de aplicación del método adaptado.

Palabras clave: Periodismo. Tétrade de McLuhan. Ecosistema mediático.

\section{Introdução}

Este texto tem como objetivo discutir o método tetrádico apresentado por McLuhan e McLuhan (1988) como ferramenta para a investigação de possíveis reconfigurações nos processos, práticas e produtos jornalísticos no ecossistema midiático atual. Propõe-se a compreensão das dinâmicas do jornalismo na contemporaneidade a partir do cruzamento entre os estudos das organizações e instituições jornalísticas - que movimentam noções de legitimação, visibilidade, institucionalização - e da Ecologia da Mídia³.

Primeiramente, aborda-se a perspectiva da Ecologia da Mídia como base para compreender o cenário de mídia atual, com destaque para o entendimento dos meios enquanto ambientes e espécies parte de um ecossistema em permanente transformação. Logo após, são apresentados alguns marcos conceituais para a discussão acerca do jornalismo na contemporaneidade, entendido como

\footnotetext{
3 Tal reflexão faz parte de pesquisa doutoral em andamento que explora as possibilidades de uma abordagem ecológica e contextual para o estudo do jornalismo no contexto contemporâneo, somando-se a esforços anteriores (Barichello, 2014; Barichello; Carvalho, 2013) de atualizar os estudos organizacionais e institucionais ao considerar as características do ecossistema midiático atual em sua plenitude, afastando-se dos modelos teóricos massivos.
} 
instituição social cujos princípios e diretrizes são materializados e atualizados pelas organizações que a representam. Assim, discute-se como, por meio de processos de legitimação, mudanças organizacionais e institucionais se efetivam e se consolidam enquanto novas práticas ou institucionalidades, entre estratégias de ruptura, inovação, adaptação e manutenção de essências. Em seguida, apresenta-se o método tetrádico e, a fim de ilustrar a discussão, apresenta-se um esboço de aplicação da tétrade no contexto de uma organização jornalística que faz parte do corpus de pesquisa desenvolvida em nível doutoral. Por fim, reflete-se sobre as potencialidades da construção de tétrades para a investigação das mutações nos contextos jornalísticos estudados, seja em nível organizacional, seja em nível institucional, ou mesmo para investigar a dinâmica entre esses dois âmbitos.

\section{A perspectiva da Ecologia da Mídia}

A Ecologia da Mídia (Media Ecology) ou Teoria do Meio 4 é uma perspectiva teórico-epistemológica abrangente, que se ocupa das relações entre os meios de comunicação até as transformações mais profundas na percepção e cognição de sujeitos e coletividades causadas pelos usos e apropriações das tecnologias. Uma vez que não se refere a um período ou meio específico, Scolari (2015) a considera uma teoria transmídia, cuja reflexão vai desde a aparição da linguagem humana, passa pela transição da oralidade à escrita, chega até os tempos atuais e é até capaz de antecipar cenários futuros.

Por tal amplitude, a Ecologia da Mídia pode ser adotada pelas mais variadas disciplinas que tenham os meios de comunicação como ponto de partida para investigar as transformações nas sociedades e culturas ao longo dos tempos. Contudo, é justamente nas ciências da comunicação que encontra campo mais fértil. Destacam-se, neste trabalho, duas interpretações centrais da metáfora ecológica que são particularmente úteis para os estudos das práticas, processos e produtos jornalísticos: o entendimento dos meios de comunicação enquanto ambientes e espécies e o conceito de ecossistema de mídia.

Considera-se que Marshall McLuhan foi o primeiro a chamar a atenção para o entendimento dos meios enquanto envoltórios culturais, reconfiguradores do contexto em que se inserem, com a frase "o meio é a mensagem".

\footnotetext{
4 Também conhecida como Escola de Toronto, Escola de Nova York, Escola Norte-americana de Estudos Culturais e Mediologia (ISLAS, 2015).
} 
Contudo, em sua obra, o autor não apresenta uma definição concisa do termo (MOLONEY, 2015), inspirando, assim, inúmeras interpretações desde a publicação de Understanding Media, em $1964^{5}$.

Afirmar que o meio é a mensagem não significa entender essas categorias como sinônimas, mas chamar a atenção para o complexo relacionamento entre esses dois elementos e promover uma mudança de foco do conteúdo para o entorno, como esclarece Strate (2008). Isso porque é o meio, ao proporcionar interações e alterações nas mensagens, que tem maior impacto nas ações e escoIhas individuais e coletivas. Nesse sentido, apreender o meio de forma ecológica é reconhecer que cada tecnologia representa um contexto cujos efeitos - seja no âmbito das técnicas, seja na produção de sentidos - são maiores e mais importantes que o artefato em si ou que o conteúdo de suas mensagens.

Por exemplo, não é o nascimento do jornal impresso, enquanto objeto material, ou as informações que por meio dele circulam que produzem os efeitos mais profundos e duradouros sobre a sociedade. É o jornal enquanto forma simbólica, ambiente (re)configurador de práticas sociais e culturais: desde os estilos de redação que se adaptam às possibilidades e às restrições do meio aos hábitos de leitura (do leitor de jornal); do surgimento de profissões especializadas à formação de uma indústria para sua produção; e por aí vai.

Outro significado embutido na noção de meio como ambiente é a ideia de que um meio sempre traz consigo, como conteúdo, outro meio. Para McLuhan (2007), ao atuar como conteúdo, o meio anterior é mais facilmente percebido, uma vez que raramente as pessoas percebem as características do novo meio e têm consciência do ambiente em que estão envolvidas. Faz parte da natureza do meio, enquanto ambiente, ser invisível à consciência: “O 'conteúdo' da escrita ou da imprensa é a fala, mas o leitor permanece quase que inteiramente inconsciente, seja em relação à palavra impressa, seja em relação à palavra falada" (MCLUHAN, 2007, p. 33).

Quando um meio se transforma em conteúdo de outro meio, ele se torna o código, a forma simbólica ou estilo estético usado para a criação das mensagens (STRATE, 2008). Na infância do jornalismo digital, os primeiros jornais a contarem com versões online apenas reproduziam o conteúdo do impresso em seus domínios na internet. Novos meios tendem a espelhar a linguagem e as práticas consolidadas dos antigos, até que descubram formas mais apropriadas de comunicar. Quando isso acontece, velhos meios também são afetados. À medida que meios analógicos tornam-se cada vez mais digitais (COULDRY; 
HEPP, 2017), por exemplo, confirma-se o que McLuhan assinalava no início dos anos 60: "Um novo meio nunca se soma a um velho, nem deixa o velho em paz. Ele nunca cessa de oprimir os velhos meios, até que encontre para eles novas configurações e posições" (MCLUHAN, 2007, p. 199).

Além da noção dos meios de comunicação como ambientes para as práticas e processos, pensar o jornalismo a partir do enfoque ecológico inclui o entendimento de que as organizações e as instituições jornalísticas se inserem em um ecossistema midiático onde há espaço para novas e velhas mídias - que não desaparecem, mas se transformam. Considerando a digitalização como ponto de partida para as reconfigurações mais significativas da sociedade e da cultura nos tempos atuais (COULDRY; HEPP, 2017), adiciona-se o adjetivo digital para tratar do ecossistema de mídia verificado na contemporaneidade. Nele, "[...] meios e ambientes geram novas e variadas relações resultantes de sua natureza instável, móvel e global, gerando um constante estado de desequilíbrio que rapidamente se reequilibra para logo se desequilibrar novamente" (CANAVILHAS, 2010, p. 2).

A crescente complexificação do ecossistema midiático digital, em suas múltiplas possibilidades de interação e fluxos, afeta diretamente o jornalismo. Em nível organizacional, os efeitos vão desde o âmbito da produção, incluindo a organização de novas rotinas e formas de apurar, editar e contar histórias, às formas de circulação e hábitos de consumo dos produtos midiáticos. Em nível institucional, passam pelas possíveis reconfigurações acerca dos entendimentos do fazer jornalístico e pelas reflexões a respeito de sua legitimidade.

\section{O jornalismo enquanto instituição do ecossistema midiático}

Diante de uma miríade de transformações disseminadas e diversas, como bem apontam Anderson, Bell e Shirky (2013, p. 70), é praticamente impossível apresentar uma lista definitiva dos desafios enfrentados pelo jornalismo hoje: "O principal efeito da mídia digital é que não há nenhum efeito principal". A chegada da internet e a aceleração dos processos provocada pela digitalização puseram abaixo muitas certezas sustentadas por décadas e décadas. Para Saad (2016, p. 74), tal cenário é responsável por abalar o jornalismo "[...] seja enquanto poder legitimado formador de opinião, seja como indústria inserida nos processos empresariais de lógica capitalista”.

A fim de refletir sobre o jornalismo enquanto instituição no ecossistema midiático atual é relevante, de início, aclarar alguns conceitos. De forma sintética, conforme Guerra (2005), a instituição está acima da organização, sendo que esta última pode ser considerada a manifestação empírica da primeira. Desse 
modo, entende-se por instituição jornalística o conceito, os princípios e a função da atividade que, a partir da definição de características universalizáveis, delimita o que pode ser entendido e/ou identificado como jornalismo. Por sua vez, tem-se como organização jornalística aquela que, por meio de recursos de infraestrutura, tecnológicos e humanos, materializa tal conceito, princípios e função da instituição. Assim, enquanto "a instituição representa uma ideia que aponta para um 'dever-ser'; a organização é o 'ser' desta instituição num determinado momento, num determinado lugar" (GUERRA, 2005, p. 2).

Tem-se no século XIX, o início do processo de reconhecimento do jornalismo enquanto instituição social. Isso ocorre a partir da definição de funções socialmente reconhecidas e compartilhadas, tanto para o jornalismo como para aqueles que o praticam, e o consequente surgimento de escolas de formação destinadas a disseminar, geração após geração, as práticas e processos considerados jornalísticos. Esse reconhecimento do jornalismo corrobora com Berger e Luckmann (2014, p. 93), quando afirmam que "[...] toda instituição tem um corpo de conhecimento transmitido como receita, isto é, conhecimento que fornece as regras de conduta institucionalmente adequadas". Tal corpo de conhecimentos, histórico e socialmente partilhado, define quais condutas são ou não jornalísticas e quais são os papeis possíveis de serem desempenhados no contexto institucional. Inclui valores, crenças e mitos acerca da atividade e o vocabulário utilizado para designar os produtos jornalísticos, as técnicas, as habilidades desejáveis de um jornalista, o que é ou não noticiável, o emprego das tecnologias, entre outros.

Apesar de haver princípios nucleares sobre a atividade jornalística, o entendimento acerca dessa instituição e de quaisquer outras instituições não permanece estanque ao passar dos tempos. Como bem colocam França e Correia (2012, p. 8), “[...] as instituições são construídas, modificam-se historicamente, e tanto moldam as situações como se adaptam aos novos momentos vividos por uma sociedade". Tal afirmação salienta a relevância da reflexão sobre os processos institucionais e organizacionais ser precedida do reconhecimento do ecossistema em que esses têm lugar.

\section{Legitimação, visibilidade e novas instituições no ecossistema}

Entender como o jornalismo se transforma e se reconfigura passa pela investigação de como seu mundo institucional se legitima, ou seja, pelos modos por meio dos quais pode ser explicado e justificado (BERGER; LUCKMANN, 2014; BARICHELLO, 2004; 2008). Faz-se necessário esclarecer que o mundo institu- 
cional do jornalismo inclui, além das organizações que materializam seu conceito e diretrizes, várias instituições: desde as ações habituais e atores tipificados que representam, cada um deles, uma instituição (tais como a notícia, o jornalista, o próprio fazer noticioso enquanto técnica específica, etc.), bem como os meios de comunicação que fazem parte da atividade jornalística e operam enquanto instituições do ecossistema midiático, a partir de seus usos e apropriações tecnossociais (BARICHELLO; CARVALHO, 2013).

O entendimento do processo de legitimação passa pela noção de visibilidade. Ao fazerem visíveis certas práticas, pensamentos, visões de mundo, as organizações e instituições midiáticas proporcionam reconhecimento e se constituem palcos privilegiados para a legitimação de outras organizações e instituições sociais. Ao mesmo tempo em que tornam visíveis as práticas de outros atores, a própria mídia faz-se visível por meio de seus suportes, em um processo autorreferencial (BARICHELLO, 2008; BARICHELLO; CARVALHO, 2013).

Essa ênfase no poder da mídia em conferir efeitos de realidade e credibilidade é inerente ao próprio desenvolvimento dos meios de comunicação massivos. Todavia, no ecossistema midiático vigente, em que se observam a descentralização dos suportes de visibilidade e a diversificação dos contextos de recepção, estar visível não é o bastante. Para Barichello e Carvalho (2013), no ecossistema de mídia atual é necessário que as organizações se apropriem das potencialidades dos diferentes meios e estimulem a inteligência coletiva, seja por meio da distribuição multiplataforma, seja por meio do ingresso em novos segmentos midiáticos. $\mathrm{Na}$ teoria, esse é o cenário ideal. Na prática, como observam Anderson, Bell e Shirky (2013), adaptar-se ao ecossistema em transformação implica mexer em práticas e processos estáveis nas redações, o que raramente é simples. Significa estar presente em novos territórios e conviver com novos atores na rotina produtiva, na qual estratégias de visibilidade são efetivadas não só nos meios tradicionais em que a organização materializa seu fazer e discurso (no jornal, no rádio, na TV, no webjornal), como também em plataformas externas, como as mídias sociais digitais $^{6}$. À medida que ações de apropriação das práticas e linguagens típicas desses ambientes passam a integrar os regimes de visibilidade das organizações, processos de legitimação passam a ser buscados de forma mais intensa nesses espaços, tendo como base a exploração de valores como credibilidade e qualidade

\footnotetext{
6 A partir de uma perspectiva ecológica, Barichello e Carvalho (2013) propõem a denominação mídia social digital para caracterizar uma nova ambiência de fluxos comunicacionais, a partir de ferramentas disponíveis em redes digitais, considerando-as como um meio com estrutura e códigos próprios. Tais mídias se diferenciam dos meios de comunicação de massa especialmente por suas possibilidades de usos e apropriações, por parte dos usuários.
} 
por meio da exposição de justificativas sobre o fazer noticioso, relacionadas à forma de produção adequada, coerente, contextualizada, responsável e fiel aos princípios do campo institucionalizado (DALL'AGNESE, BARICHELLO, BELOCHIO, 2016), que continua essencial para dar significado à avalanche informacional que caracteriza a sociedade digitalizada.

Vale demarcar que, neste estudo, o foco não é discutir se o jornalismo, ao ser impactado pela digitalização, tem sua legitimidade, papel legitimador ou mesmo institucionalidade ameaçados - quer seja pela apropriação de seus saberes por outros atores sociais (FAUSTO NETO, 2011), quer seja pelos desafios sociotécnicos que abalam suas práticas ou modelos de negócio. Como bem pontua Saad (2016, p. 80), dentre as especificidades do mundo midiático, é certo que “[...] o jornalismo, enquanto instituição legitimada pela sociedade (hoje digitalizada), sobrevive não importa o cenário". Desse modo, concentra-se, aqui, na reflexão sobre suas reconfigurações estruturais, desafio que passa pela investigação de como o jornalismo se adapta, inova ou mesmo resiste às mudanças do ecossistema midiático, a partir das dinâmicas entre questões organizacionais e regras institucionais que atualizam o que se entende por jornalismo e até mesmo fazem surgir novas institucionalidades, a partir de híbridos de velhas e novas práticas, processos ou produtos.

Assim, interessa refletir sobre como se processa a mudança em âmbito organizacional e institucional. Guerra (2005, p. 15) explica que, apesar de qualquer transformação na instituição jornalística partir das ações organizacionais, "lances de vanguarda" só se efetivam quando se tornam universalizáveis, quando se estabilizam como práticas, processos ou produtos legitimados. Logo, tudo que hoje atua como instituição neste ecossistema midiático único que representa a época atual, um dia foi novidade, enfrentou resistência e precisou ser reconhecido como legítimo pela sociedade - até tornar-se internalizado pelos atores sociais, "natural" às ações cotidianas, como se sempre tivesse existido. Por exemplo, o reconhecimento das mídias sociais como ambientes institucionais implicou a legitimação de um certo conjunto de práticas das organizações jornalísticas nesses ambientes.

Da mesma forma, há quinze ou vinte anos talvez fosse difícil conceber transformações nas estruturas da periodicidade, nas técnicas de apuração, edição, publicação e outras características centrais que definem a atividade. Contudo, a partir do aprofundamento da digitalização, entram em cena a publicação em fluxo contínuo, a incorporação de ferramentas colaborativas, as bases de dados, os softwares e os algoritmos. O conjunto de práticas, produtos e processos, os perfis de seus profissionais e organizações, bem como os meios tradicionalmente 
associados ao jornalismo, são atualizados e/ou ampliados à medida que novas categorias são legitimadas para se enquadrar nesse mundo institucional.

Rupturas nas instituiçõos jornalísticas podem ser associadas a processos de adaptação de "velhas" instituições e de inovação que podem fazer surgir novas institucionalidades. A adaptação é vista por Anderson, Bell e Shirky (2013) como uma fonte valiosa para o crescimento e a evolução institucional e passa pela utilização e apropriação dos recursos do ecossistema que se forma com a internet. Já a inovação jornalística, que vai além da adaptação institucional e não se vincula somente ao incremento tecnológico, é entendida por Saad (2016, p. 80) como decorrente de "um conjunto de atitudes, posicionamentos, atenções, pesquisas e prospecções que poderíamos agregar no termo planejamento estratégico - uma atividade contínua e sistemática”.

Conforme Saad (2016), para atingirem um estado de inovação contínua, as organizações jornalísticas precisam se engajar de forma profunda aos parâmetros da sociedade digitalizada7, sem abandonar sua essência jornalística, seja em meios impressos, seja em meios digitais. Isso envolve duas atitudes primordiais: a aceitação do seu estado de impermanência e uma plena atenção às transformações cotidianas do ecossistema. Exemplos paradigmáticos de inovação podem ser encontrados em organizações como The New York Times e The Guardian. Contudo, para a autora, apesar de representarem casos inspiradores reconhecidos internacionalmente, esses paradigmas não são copiáveis, pois resultam de condições variadas das culturas locais e da indústria de mídia das regiões onde estão localizados.

Em suma, conclui-se que um misto de assimilação de novidades e manutenção de essências configura o jornalismo no ecossistema midiático atual como instituição que persiste relevante e essencial para a sociedade, mas que, por meio de rupturas, adaptações e inovações em suas práticas, processos e produtos, enfatiza a impermanência das coisas. Nesse contexto em que a abordagem ecológica faz todo sentido, destaca-se, além das noções apresentadas anteriormente (de meio e ecossistema), o método tetrádico de McLuhan e McLuhan (1988) como instrumento para, por meio da análise de práticas, processos ou produtos jornalísticos, apontar possíveis reconfigurações, seja em âmbito organizacional (quando a análise restringir-se ao cenário de uma organização jornalística), seja em âmbito institucional (quando a análise objetivar a comparação entre diversas organizações, a fim de verificar impactos mais amplos), dependendo dos objetivos da pesquisa.

7 Segundo Saad (2016), trata-se de uma atitude referente à proposta de full service journalism organization do Nieman Journalism Lab, Universidade de Harvard (EUA). 


\section{O método tetrádico de McLuhan e McLuhan (1988)}

A elaboração das leis ou efeitos da mídia representada pela forma tetrádica originou-se de um trabalho de revisão da obra Understanding Media, empreendido por Eric e Marshall McLuhan, na última década de vida do último ${ }^{8}$. A fim de dar uma resposta às críticas acerca da ausência de cientificidade (em seu sentido mais convencional) do livro publicado em 1964, como explica Eric McLuhan (1988), a criação de Laws of Media partiu da busca dos dois por afirmações que pudessem ser testadas (provadas ou refutadas) por qualquer pessoa, em qualquer lugar e a qualquer tempo, quando utilizadas para analisar qualquer artefato ou enunciado humano. Noutros termos, que pudessem ser apresentadas enquanto princípios científicos. Com esse intuito, inicialmente, quatro características foram apontadas: extensão (toda tecnologia estende ou amplifica algum órgão ou faculdade do usuário); encerramento (quando uma área de experiência é realçada ou intensificada, outra é diminuída ou paralisada); reversão (toda forma, pressionada ao limite de seu potencial, inverte suas características); e recuperação (relacionada à reformulação de tudo o que representa o conteúdo da nova forma, uma vez que o conteúdo de qualquer meio é o meio anterior). (MCLUHAN; MCLUHAN, 1988).

Elaboradas como perguntas e organizadas na forma de tétrade (Quadro 1), esses aspectos deram origem às quatro leis da mídia, aplicáveis a qualquer meio, tecnologia ou artefato, em sentido material (por exemplo, uma caneta, um computador) ou abstrato (uma proposição, uma lei científica); hardware ou software; a qualquer palavra ou frase, em qualquer linguagem. Para os autores, "tudo que o homem faz e constrói, cada procedimento, cada estilo, cada artefato, cada poema, música, pintura, truque, dispositivo, teoria, tecnologia - cada produto do esforço humano - manifesta essas quatro dimensões" (MCLUHAN; MCLUHAN, 1988, p. ix)9.

\footnotetext{
8 As leis ou efeitos da mídia foram apresentados por Marshall McLuhan pela primeira vez em um artigo de 1977 (LEVINSON, 1999); contudo, o pesquisador falecera antes da publicação do livro. Eric McLuhan conta, no prefácio de Laws of Media, que o pai passou os seus últimos anos procurando por uma quinta lei, ao mesmo tempo em que buscava encontrar algum exemplo ao qual uma das primeiras quatro não fosse aplicável. (MCLUHAN; MCLUHAN, 1988)

9 Do original: We found that everything man makes and does, every procedure, every style, every artifact, every poem, song, painting, gimmick, gadget, theory, technology - every product of human effort - manifested the same four dimensions.
} 
Quadro 1 - As quatro faces da tétrade

\begin{tabular}{c|c}
$\begin{array}{c}\text { MELHORA } \\
\text { (Enhances) }\end{array}$ & $\begin{array}{c}\text { REVERTE-SE } \\
\text { (Reverses into) }\end{array}$ \\
$\begin{array}{c}\text { O que o artefato aperfeçoa, intensifica, torna possível } \\
\text { ou acelera? }\end{array}$ & $\begin{array}{c}\text { Quando levada aos limites de seu potencial, a nova } \\
\text { forma tende a reverter-se. Qual é o potencial de } \\
\text { reversão da nova forma? } \\
\text { (Retrieves) } \\
\text { Que ações ou serviços anteriores retornam ou são } \\
\text { recuperados pelo novo artefato? Que contexto } \\
\text { obscurecido anteriormente é trazido de volta e é } \\
\text { inerente à nova forma? }\end{array}$ \\
\hline OBSCURECE \\
(Obsolesces)
\end{tabular}

Fonte: Elaborado pelos autores com base no livro Laws of Media (MCLUHAN; MCLUHAN, 1988).

As faces da tétrade não representam processos sequenciais, mas simultâneos, inerentes ao objeto de análise desde o início. Então, extensão/melhora, que tem a ver com o aperfeiçoamento das habilidades humanas, relaciona-se diretamente com a obsolência, uma vez que, ao promover o aperfeiçoamento da função ou funções de um meio, tecnologia ou artefato, o que veio antes é tornado obsoleto. Ao mesmo tempo, aperfeiçoar algo já existente implica a recuperação de uma forma do passado. Um exemplo: Ghisleni e Barichello (2013, p. 92) verificam em estudo sobre o Facebook que, ainda que essa mídia social inove, "com ferramentas que se adaptam constantemente às necessidades dos usuários e geram novos efeitos na sociedade, também resgata usos tradicionais de outros meios de comunicação que se tornaram obsoletos".

Sobre o princípio da reversão, Logan (2011, p. 7) explica que "[...] quando levado longe o bastante, o novo meio, tecnologia ou artefato feito pelo homem se inverte, dá uma reviravolta, tornando-se uma forma complementar ou possivelmente oposta”. Contudo, essa oposição não é absoluta, como contrapõe Levinson (1999), já que a reversão expressa continuidade de elementos que, antes obscurecidos, são recuperados. Trata-se do novo meio ou efeito incorporando aspectos do meio imediatamente anterior, em uma espécie de espelho retrovisor em ação.

A aplicação do método tetrádico, propício para revelar e prever a dinâmica das mais variadas situações em que novos ambientes estão sendo estruturados (ou, poder-se-ia também dizer, em que antigos estão sendo reestruturados), pode resultar em uma ou em um grupo de tétrades interconectadas. A quarta parte da tétrade, reversão, inspira outro mapeamento de quatro partes, e assim 
por diante. Sem esquecer a noção ambiental no processo de análise dos meios, tecnologias ou artefatos também é preciso compreender que o que é recuperado não são apenas funções ou propriedades específicas, mas elementos de ambientes de mídia anteriores que passam a funcionar de forma diferente no novo ambiente. Nesse sentido, a construção da tétrade exige um esforço de olhar, simultaneamente, para o passado (aos contextos que levaram à criação de certo meio, tecnologia ou artefato), para o presente (aos usos, apropriações e relações propiciadas pelas potencialidades e restrições do objeto analisado) e para um possível futuro (a partir da identificação de processos em curso, seja de aperfeiçoamento, obsolescência, recuperação ou reversão).

A partir de sua amplitude de aplicações e enquanto instrumento para analisar fenômenos complexos, aponta-se, neste trabalho, a possibilidade de adoção do método tetrádico para verificar reconfigurações nas práticas, processos e produtos jornalísticos tanto no nível das instituições (transformações no conceito de notícia, nos perfis profissionais, no que é ou não considerado jornalismo) quanto no nível das organizações (mutações verificadas em uma empresa jornalística particular). Nesses dois níveis ou contextos, que podem ser divididos em macro (institucional) e micro (organizacional), a validade da tétrade é defendida a partir da hipótese de que relações podem ser feitas entre as quatro leis da mídia e possíveis indicadores de reconfigurações no âmbito jornalístico, expressas em: estratégias de ruptura com processos, práticas ou produtos anteriores; estratégias de adaptação às mudanças no ecossistema; estratégias de inovação nesse ecossistema; bem como a identificação de estratégias de manutenção dos princípios e diretrizes institucionais ou organizacionais. Assim como as faces da tétrade, tais estratégias encontram-se inter-relacionadas, sendo postas em prática de forma simultânea e complementar.

A definição do contexto (micro ou macro) a partir do qual se tem como intuito analisar os processos, práticas e/ou produtos objetos da investigação serve para orientar as reflexões que comporão a(s) tétrade(s). Por exemplo, pode-se optar por analisar a prática da checagem de fatos (fact-checking), na atualidade, a partir do contexto jornalístico macro ou "a prática da checagem de fatos", no contexto micro, de uma organização x. Pensar em nível macro é considerar mutações mais amplas, institucionais. Tendo-o como norte, os apontamentos terão como origem a reflexão acerca do que essa prática aperfeiçoa, recupera, torna obsoleto ou reverte em relação às práticas que podem ser reconhecidas, de forma mais geral, como jornalísticas. Logicamente, análises nesse sentido exigirão maior esforço e a consideração de um frame temporal mais amplo. Já o 
nível micro permite um olhar mais localizado, uma vez que se restringe às mutações dentro de uma empresa jornalística. As reflexões, assim, irão considerar o que é aperfeiçoado dentro do conjunto de práticas adotadas pela organização desde seu início, ou em um período delimitado. A dificuldade poderá variar de acordo com o tempo de existência da organização e o maior ou menor intervalo em que são verificadas rupturas e inovações em suas rotinas produtivas.

Para investigações de maior extensão e complexidade, a combinação dos dois contextos convida à percepção das dinâmicas entre questões organizacionais e diretrizes institucionais, instigando questões relacionadas ao modo como o mundo institucional jornalístico atualiza-se e evolui por meio das ações organizacionais.

\section{Esboço de aplicação da tétrade: caso de análise em nível micro}

A fim de ilustrar brevemente como a tétrade pode ser utilizada como instrumento analítico de pesquisa, toma-se um exemplo oriundo das descobertas do projeto de pesquisa doutoral em andamento que objetiva analisar a produção transmídia em diferentes organizações jornalísticas. Uma delas é o jornal britânico The Guardian, do qual se selecionou uma situação específica - a implementação da ferramenta de análise de dados Ophan na redação - para construir um esboço de aplicação da tétrade adaptada aos propósitos investigativos. Trata-se, portanto, de uma aplicação em nível micro, no contexto de uma organização particular, e que pretende olhar para as mudanças ocorridas apenas neste local. A coleta de dados utilizados para basear a tétrade se deu a partir de observação do portal theguardian.com, pesquisa bibliográfica e informações obtidas por e-mail.

Parte do Guardian Media Group, o jornal The Guardian é gerenciado pela fundação Scott Trust Limited, criada para assegurar a independência financeira e editorial deste e dos outros dois periódicos do grupo. Sob este nome, existe desde 1959, mas suas origens como Manchester Guardian datam do século XIX. O jornal, com presença online desde o final da década de 1990, adotou o modelo de redação integrada em 2008 (SALAVERRÍA; NEGREDO, 2008) e, em 2011, a estratégia de publicação digital-first (HISTORY OF THE GUARDIAN, 2017). Além do Reino Unido, possui operações na Austrália e nos Estados Unidos e, desde 2013, quando mudou o domínio de seu website para .com após o impacto da cobertura NSA Files, investe na expansão de seus produtos digitais multiplataforma a fim de se consolidar como marca global (MURRELL, 2016). Como resultado, segundo o próprio jornal, em 2017 as contribuições de cerca de meio milhão de assinantes e membros do periódico ultrapassaram o número de anunciantes como forma de 
financiamento (VINER, 2017). Apesar de não adotar paywalls, o jornal aposta em estratégias diversas para engajar leitores a investir no jornalismo "independente, investigativo e de qualidade", três características frequentemente destacadas em anúncios que vão de boxes coloridos a parágrafos no final das matérias.

Especificamente nas plataformas digitais, a busca pelo engajamento dos leitores passa também pelo uso de uma variedade de ferramentas de métricas e análise de dados que dão suporte ao planejamento editorial e comercial da organização. Entre elas, destaca-se a plataforma construída internamente, em 2012, pela equipe de desenvolvimento digital do The Guardian: o Ophan. De forma geral, trata-se de uma ferramenta para obter informações acerca do comportamento dos leitores em relação aos conteúdos publicados no portal. Não que o The Guardian ignorasse esse tipo de informação até então - o software Onminture, da Adobe, já era utilizado na época para acompanhar o tráfego nas plataformas digitais (SAWERS, 2015). Contudo, com o Ophan, há uma mudança qualitativa no tipo de dados obtidos, marcando uma nova fase na utilização de métricas online para o planejamento editorial na redação. Assim, critérios baseados na atenção, engajamento e fidelidade dos leitores complementam métricas mais genéricas como page views e compartilhamentos (apesar de essas também serem fornecidas pela plataforma).

Um fator crucial que difere o Ophan de ferramentas analíticas anteriores, apontado por Cherubini e Nielsen (2016), é que este foi pensado por pessoas da equipe editorial do The Guardian para ser utilizado por jornalistas, não por especialistas em análise de dados. Sem a necessidade de pagar por licenças adicionais, o Ophan permite que todos os repórteres, dentro ou fora do prédio do The Guardian, acompanhem os artigos de interesse minuto a minuto, prática que antes raramente chegava à redação - pelo menos, não além dos cargos gerenciais (MURELL, 2016). Com uma interface amigável, possível de ser acessada por dispositivos móveis, a plataforma oferece dados, por exemplo, acerca do tempo gasto em cada página; a partir de que dispositivos a leitura se dá; como as pessoas chegaram a um conteúdo específico (se a partir do Google, de post em mídia social ou de outro conteúdo do próprio Guardian, por exemplo); de que localização geográfica (país/região/ cidade); e, no caso de usuários registrados no website, o que foi lido na sequência. Além de informações sobre a audiência, dados sobre como cada item está sendo promovido pelo próprio The Guardian também estão disponíveis.

Dessa forma, segundo o editor de projetos estratégicos do The Guardian e um dos idealizadores do Ophan, Chris Moran, a ferramenta traz incrementos 
especialmente na forma de como as histórias são promovidas ${ }^{10}$. Com grande nível de detalhamento, repórteres podem visualizar, por exemplo, os posts do Twitter que atraíram mais leitores ao portal, atuando como ferramenta para entender quais formatos funcionam melhor em cada tipo de conteúdo. Quando solicitado por e-mail" acerca de uma das coberturas ${ }^{12}$ acompanhadas por nós em projeto de pesquisa doutoral em andamento. Moran (2018) explicou que não está autorizado a informar a lista completa de dados que o Ophan pode fornecer, nem gerar uma captura da tela de seus relatórios. Contudo, pôde informar que o acesso direto ao domínio do The Guardian, seguido das plataformas Google e Facebook, lideram quando o questionamento é como os leitores chegam até as publicações (métrica chamada de referral traffic).

Para Cherubini e Nielsen (2016), boas práticas no uso de dados em favor do jornalismo resultam de uma combinação de (1) ferramental tecnológico; (2) estrutura organizacional compatível e (3) desenvolvimento de uma cultura de dados na redação. Logo, por maior que seja a extensão de informações que o Ophan possa fornecer, os dados, por si só, não bastariam sem o suporte e investimento necessários para interpretá-los e torná-los parte da tomada de decisões diária e a médio e longo prazos da produção jornalística. O que envolve desde a extensão de uma cobertura até decisões acerca da contratação de profissionais para editorias específicas (MURRELL, 2016). Entretanto, a larga adoção da ferramenta pelos jornalistas no The Guardian não acontece do dia para a noite. Trata-se de um novo elemento que demanda mudanças em práticas e processos organizacionais estabilizados e, como tal, enfrenta resistência. "Ao longo dos meus primeiros quatro anos de trabalho no The Guardian, encontrei quase toda objeção possível ao que eu estava fazendo"13, relata Moran (2017).

Da implementação do Ophan na redação do The Guardian, esboça-se uma aplicação do método tetrádico adaptado, com objetivo de apontar o que pode ser identificado como estratégias organizacionais em cada um dos quatro aspectos apresentados a seguir. Nesta adaptação, então, melhora, da tétrade original, relaciona-se com os incrementos realizados pela organização jornalística a fim de adaptar-se às mudanças do ecossistema midiático; recuperação é interpretada

\footnotetext{
10 Entrevistado por Edge (2014).

$"$ Informação solicitada, a nosso pedido, pela professora Mercedes Bunz, ex-repórter do The Guardian e coorientadora durante período da doutoranda CarolinaDall Agnese como visiting research student, na University of Westminster. E-mail encaminhado em 25 de abril de 2018.

12 Primeira semana de publicações da cobertura Cambridge Analytica Files.

13 Do original: Over the first four years of my work at the Guardian, I encountered almost every possible objection to what I was doing.
} 
como manutenção das essências organizacionais; no lugar de obsolescência, tem-se ruptura com práticas, processos ou produtos anteriores; e, por fim, reversão é relacionada com inovação: o que surge de novo quando as potencialidades do meio, ferramenta ou fenômeno analisado são apropriadas/exploradas ao limite?

\section{Quadro 2 - Esboço de aplicação da tétrade adaptada: implementação do Ophan na redação do The Guardian}

\begin{abstract}
Adaptação
Do caso analisado, podemos identificar adaptações tanto em relação ao ecossistema midiático como em relação ao próprio ambiente interno da redação. Com a criação de uma ferramenta própria, alinhada às necessidades editoriais, o The Guardian demonstra postura ativa frente às transformações do ecossistema. Ao possibilitar a obtenção de mais informações acerca do comportamento da audiência, entende-se que o Ophan incrementa a capacidade do The Guardian de entender o ecossistema de mídia em que se insere. Estratégias de adaptação em relação ao próprio ambiente da redação, reconfigurado, também podem ser apontadas.
\end{abstract}

\section{Inovação}

O The Guardian inova ao criar uma ferramenta própria, pensada para o uso jornalístico, e, com isso, incorporar o uso sistemático da análise de dados na tomada de decisões cotidiana e em longo prazo. Em torno do Ophan, cria-se um novo ambiente, uma vez que a implementação da ferramenta origina novas/modifica antigas práticas, processos e produtos no contexto da redação. Por exemplo, novas habilidades são exigidas dos jornalistas para interpretação dos dados; surgem novas demandas de planejamento; cria-se a necessidade de revisar constantemente a ferramenta para correções e incrementos; pode-se citar, ainda, todos os esforços visando a fomentar uma "cultura de dados" no ambiente organizacional.

\section{Ruptura}

A manutenção tem a ver com o contexto que proporciona o desenvolvimento da ferramenta. Ao chamar a atenção de pesquisadores e de outras organizações ${ }^{*}$ como exemplo de boa prática no uso de dados (Cherubini e Nielsen, 2016), a implementação do Ophan reforça a imagem do The Guardian como de vanguarda (SAAD, 2016). Textos assinados por jornalistas da própria organização mencionando a ferramenta (e.g. MORAN, 2017) contribuem para colocar em visibilidade valores e práticas legitimadas. Acerca do trabalho realizado com auxílio do Ophan, tratase de uma adição aos esforços anteriores da organização a fim de medir seu impacto, a qual convive com outras práticas ainda vigentes - métricas acerca número de vendas, pesquisas de opinião, etc.
A implementação do Ophan provoca ruptura com processos anteriores em que jornalistas não se envolviam diretamente no acompanhamento de dados referentes ao acesso às plataformas digitais do The Guardian. A democratização do acesso, possibilitado principalmente pelo fim da necessidade de pagar por licenças adicionais (o que ocorre com softwares de terceiros), faz com que a analítica não se restrinja mais às equipes comerciais ou aos cargos de gerência da organização. O Ophan também diminui a importância de métricas mais genéricas dos dados em favor de análises mais complexas que se adaptam aos interesses editoriais e elimina o uso de ferramentas externas como principais fontes de obtenção de dados, ainda que continuem a ser utilizadas como acessórias.

* Segundo Chris Moran, editor de projetos estratégicos, outras organizações de mídia manifestaram interesse em obter licença para utilização do Ophan; contudo, não houve interesse do The Guardian em abrir a ferramenta para uso de terceiros (EDGE, 2014).

Fonte: Elaborado pelas autoras.

O período a que a tétrade se refere pode ser definido como os últimos seis anos, da implementação do Ophan até hoje. Contudo, leva-se em consideração o histórico mais amplo que proporciona a criação e desenvolvimento de tal ferramenta. Como mencionado anteriormente, tem-se uma organização que adota a inovação contínua, como apontado por Saad (2016), mostrando uma postura 
ativa diante das transformações do ecossistema. Que exemplifica o poder de uma organização jornalística de se (re)inventar e de (re)legitimar sua relevância nos tempos atuais, mas, que de forma alguma pode ser tomado como termômetro do estado do jornalismo atual, uma vez que ocorre em um contexto bastante particular. Por isso, reforçamos o caráter micro deste esboço. Tais observações fazem parte do reconhecimento do ecossistema em que os fenômenos analisados têm lugar.

Destaca-se, ainda, que a relação proposta aqui com estratégias de ruptura, inovação, adaptação e manutenção de essências do jornalismo alinha-se ao escopo teórico e aos objetivos desta pesquisa. Outras pesquisas poderão encontrar novas relações. Aí reside o maior potencial da tétrade: um instrumento adaptável, aberto a ajustes e incrementos, como destacaram McLuhan e McLuhan (1988), propício para olhar para um ecossistema em constante mutação.

\section{Considerações pontuais}

Para investigar o estado do jornalismo contemporâneo são necessárias abordagens globais que deem conta da complexidade que assumem as relações institucionais e organizacionais no ecossistema em constante movimento. Para isso, supera-se o entendimento das mídias como meros canais, transmissores de informação, instrumentos de persuasão de massas, e privilegia-se a reflexão sobre os papeis dos meios, tecnologias e artefatos como transformadores de fronteiras nas sociedades e culturas atuais.

Nesse sentido, sob inspiração da Ecologia da Mídia, enfatiza-se o necessário movimento da investigação das mensagens midiáticas para o foco no potencial dos ambientes para a (re)configuração de práticas, processos e produtos midiáticos - em especial, jornalísticos. A exploração da metáfora ecológica vai do entendimento dos meios como ambientes partes de um ecossistema até o uso do método tetrádico de McLuhan e McLuhan (1988), que sintetiza e torna operacionalizáveis as afirmações mais instigantes de Understanding Media.

Uma das maiores vantagens da tétrade é sua aplicabilidade a objetos e contextos diversos. Destaca-se a contribuição do método tanto para investigações que objetivem verificar transformações jornalísticas em nível macro, institucional (como o fazer noticioso se transforma ao mesmo tempo em que preserva suas características nucleares, por exemplo), como em nível micro, organizacional (como uma organização particular atualiza-se e/ou mantém suas características ao longo dos anos). Tais níveis/contextos são propostos como forma de demarcar o ponto de partida das observações que comporão a(s) tétrade(s). 
Essas instâncias, contudo, não se encontram, de fato, separadas. Apesar dessa divisão possível, destaca-se que, mesmo nas análises que objetivam verificar elementos somente em nível organizacional, está presente a intrincada relação entre as ações organizacionais e os princípios institucionais que movimenta o jornalismo enquanto instituição que evolui com o passar dos tempos, atualizando e/ou agregando novos elementos em seu mundo institucional, ao mesmo tempo em que mantém essências que se (re)legitimam há gerações.

De modo algum as possibilidades de uso da tétrade ao contexto jornalístico se esgotam aqui. Trata-se de um instrumento de investigação de complexidades e, como tal, revela novas possibilidades a cada visada. Também não se tem como intuito propor que a construção de tétrades, por si só, seja suficiente para verificar reconfigurações; prefere-se apontá-la como método analítico articulador de outros passos de pesquisa, forma de tensionar dados diversos coletados ao longo de uma investigação que tenha a Ecologia da Mídia como base.

A hipótese de relacionar as faces da tétrade com possíveis estratégias de ruptura, inovação, adaptação e manutenção tem como objetivo salientar o potencial do método para perceber essas dinâmicas que atualizam o que se entende por jornalismo e até mesmo fazem surgir novas institucionalidades, por meio do conjunto de práticas organizacionais. Ao contrastar novas e antigas práticas, processos ou produtos, a tétrade é um instrumento que permite apontar tendências, transformações consolidadas ou em curso. É uma forma para efetivamente estudar o jornalismo de forma ecossistêmica: permite ligar causas e consequências, reconhecendo que nenhuma mudança é isolada.

\section{Referências}

ANDERSON, C.; BELL, E.; SHIRKY, C. Jornalismo pós-industrial: adaptação aos novos tempos (traduzido por Ada Félix) Revista de Jornalismo ESPM, São Paulo, n. 5, p. 3089, abr./maio/jun. 2013

ALSINA, M. A construção da notícia. São Paulo: Vozes, 2009.

BARICHELLO, E.M.M.R. Midiatização e cultura nas organizações da contemporaneidade: o processo de midiatização como matriz de práticas sociais. In: MARCHIORI, M. (org.). Contexto Organizacional Midiatizado. São Paulo: Difusão: Senac, 2014. v. 8, p. 37-43.

BARICHELLO, E. M. M. R.; CARVALHO, L. M. Legitimação das organizações midiáticas no ecossistema digital. In: RUBLESCKI, A.; BARICHELLO, E. M. M. R. Ecologia da Mídia (orgs.). Santa Maria: Facos-UFSM, 2013. p. 62-77. 
BERGER, P.; LUCKMANN, T. A construção social da realidade: tratado de sociologia do conhecimento. 36. ed. Petrópolis: Vozes, 2014.

CANAVILHAS, J. O novo ecossistema mediático. [S.I.]: Biblioteca on-line de Ciências da Comunicação, 2010. Disponível em: http://www.bocc.ubi.pt/pag/canavilhas-joao-o-novo-ecossistema-mediatico.pdf. Acesso em: 7 dez. 2016.

CHERUBINI, F.; NIELSEN, R. Digital News Project 2016. Editorial Analytics: How News Media Are Developing and Using Audience Data and Metrics. Oxford: Reuters, 2016. https://doi.org/10.2139/ssrn.2739328

COULDRY, N.; HEPP, A. The Mediated Construction of Reality. London: Polity, 2017.

DALL'AGNESE, C.; BARICHELLO, E.M.M.R.; BELOCHIO, V. Transmídia, propagabilidade, engajamento. Reflexões sobre visibilidade e legitimação do jornalismo na sociedade midiatizada. In: SEMINÁRIO INTERNACIONAL DE PESQUISAS EM MIDIATIZAÇÃO E PROCESSOS SOCIAIS, 1, 2016, São Leopoldo. Anais [...]. São Leopoldo: Unisinos, 2016.

EDGE, A. Ophan: Key metrics informing editorial at the Guardian. Journalism.co.uk, Brighton, 2 dez. 2014. Disponível em: https://www.journalism.co.uk/news/how-ophan-offers-bespoke-data-to-inform-content-at-the-guardian/s2/a563349. Acesso em: 25 maio 2018.

FAUSTO NETO, A. Transformações do jornalismo na sociedade em vias de midiatização. In: FAUSTO NETO, A.; FERNANDES, J.C. (orgs.) Interfaces jornalísticas: ambientes, tecnologias e linguagens. João Pessoa: UFPB, 2011. p. 14-34.

GHISLENI, T.; BARICHELLO, E.M.M.R. Ecologia das mídias nas redes sociais digitais: estendendo a Teoria Tetrádica de McLuhan ao estudo do Facebook. In: RUBLESCKI, A.; BARICHELLO, E. M. M. R. Ecologia da Mídia (orgs.). Santa Maria: Facos-UFSM, 2013. p. $79-98$

GUERRA, J. Instituição e organização jornalística: uma distinção conceitual. In: CONGRESSO BRASILEIRO DE CIÊNCIAS DA COMUNICAÇÃO, 28, 2005, Rio de Janeiro. Anais [...]. Rio de Janeiro: Intercom, 2005. Disponível em: http://www.intercom.org.br/ papers/nacionais/2005/resumos/r1725-1.pdf. Acesso em: 5 maio 2018

HISTORY of The Guardian. GNM Archives. The Guardian, Londres, 11 dez. 2017. Disponível em: https://www.theguardian.com/gnm-archive/2002/jun/o6/1. Acesso em: 25 maio 2018.

ISLAS, O. La ecología de los medios: metadisciplina compleja y sistémica. Palabra Clave, v. 18, n. 4, p. 1057-1083, 2015. https://doi.org/10.5294/pacla.2015.18.4.5

LEVINSON, P. Digital McLuhan: a guide to the information millenium. London: Routledge, 1999. 
LOGAN, R. La base biológica de la ecología de los medios. In: SCOLARI, C. Ecología de los medios: entornos, evoluciones e interpretaciones. Barcelona: Gedisa, 2015. p. 137-152.

LOGAN, R. Figura/Fundo: Decifrar o Código McLuhan. E-compós, Brasília, v.14, n.3, set./dez. 2011. Disponível em: www.e-compos.org. Acesso em: 24 set. 2017. https:// doi.org/10.30962/ec.v14i3.709

MCLUHAN, M. Os meios de comunicação como extensões do homem (Understanding Media). São Paulo: Cultrix, 2007.

MCLUHAN, E.; MCLUHAN, M. Laws of Media: The New Science. Canadá: University of Toronto Press, 1988.

MEYROVITZ, J. Medium Theory. An alternative to the dominant paradigm of media effects. In: NABI, R.; OLIVER, M. (eds.) The SAGE handbook of media processes and effects. Califórnia: SAGE, 2009.

MOLONEY, K. Future of Story: Transmedia Journalism and National Geographic's Future of Food Project. 2015. 165 f. Tese(Ph.D.) - College of Engineering and Applied Sciences, University of Colorado Boulder, 2015.

MORAN, C. 'Raining clicks': why we need better thinking on technology, data and journalism. Medium.com, Londres, 10 ago. 2017. Disponível em: https://medium.com/@ chrismoranuk/raining-clicks-why-we-need-better-thinking-on-technology-data-and-journalism-edb379b8cdoo. Acesso em: 5 maio 2018.

MORAN, C. Entrevista concedida a Mercedes Bunz. Londres, 24 abr. 2018.

MURRELL, C. The Guardian: Game of Editions. Media LSE Working Paper Series. Londres: LSE, 2016. Disponível em: http://www.Ise.ac.uk/media@lse/research/mediaWorkingPapers/pdf/WP39-FINAL.pdf. Acesso em: 25 maio 2018.

SAAD, E. Inovação e empresas informativas: aliados, inimigos ou em permanente estado de "discussão da relação"? Revista Parágrafo, São Paulo, v. 4, n. 2, p. 72-87, jul./dez. 2016.

SALAVERRÍA, R.; NEGREDO, S. Periodismo integrado. Convergencia de medios y reorganización de redacciones. Barcelona: Editorial Sol9o, 2008.

SAWERS, P. Ophan: Inside the Guardian's data-driven newsroom. Venture Beat, San Francisco, 3 jul. 2015. Disponível em: https://venturebeat.com/2015/07/03/ophan-inside-the-guardians-data-driven-newsroom. Acesso em: 25 maio 2018.

SCOLARI, C. Ecología de los médios: entornos, evoluciones e interpretaciones. Barcelona: Gedisa, 2015.

STRATE, L. Studying media as media: McLuhan and The Media Ecology approach. In: MediaTropes eJournal, Toronto, v. 1, p. 127-142, mar. 2008. Disponível em: http://www. mediatropes.com. Acesso em: 31 out. 2017. 
VINER, C. Together, we are safeguarding the Guardian's independent journalism. The Guardian, Londres, 26 out. 2017. Disponível em: https://www.theguardian.com/membership/2017/oct/26/together-we-are-safeguarding-the-guardians-independent-journalism. Acesso em: 25 maio 2018.

\section{Dados das autoras}

Carolina Teixeira Weber Dall'Agnese: caroltweber@gmail.com

Doutoranda do Programa de Pós-Graduação em Comunicação da Universidade Federal de Santa Maria - UFSM e Mestra em Jornalismo pela Universidade Federal de Santa Catarina - UFSC.

Eugenia Maria Mariano da Rocha Barichello: eugeniamarianodarocha@gmail.com Professora do Programa de Pós-Graduação em Comunicação da Universidade Federal de Santa Maria - UFSM. Pós-Doutorado pela University College London - UCL.

Endereço das autoras: Universidade Federal de Santa Maria, Programa de Pós Graduação em Comunicação. Rua Roraima, 1000, Camobi, 97.105-900 - Santa Maria (RS) - Brasil 